\title{
Preoperative chemotherapy is essential for conservative surgery of Askin tumors
}

\author{
G. Veronesi, MD, ${ }^{a}$ L. Spaggiari, PhD, MD, ${ }^{\text {a }}$ T. De Pas, MD, ${ }^{b}$ P. G. Solli, MD, ${ }^{a}$ \\ F. De Braud, MD, ${ }^{\mathrm{b}}$ G. P. Catalano, MD, ${ }^{\mathrm{c}}$ G. Curigliano, MD, ${ }^{\mathrm{b}}$ F. Leo, MD, ${ }^{\mathrm{a}}$ and \\ U. Pastorino, MD, ${ }^{\text {a }}$ Milan, Italy
}

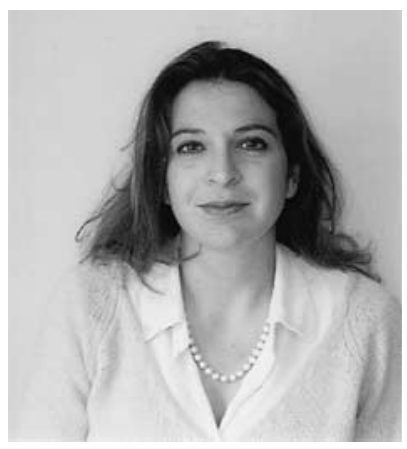

Dr Veronesi
A skin tumors are highly malignant thoracopulmonary tumors mainly occurring in children and adolescents. An aggressive multimodal approach (chemotherapy, surgery and radiotherapy) is the common treatment. ${ }^{1,2}$ Takanami and associates ${ }^{3}$ recently reported on 2 long-surviving patients with Askin tumors first treated by surgery. They suggested that the best treatment schedule was surgery followed by chemotherapy, with or without radiotherapy, highlighting the issue of the best timing of chemotherapy in this disease. In our opinion many reasons justify the use of chemotherapy in a preoperative setting, including a safer and simpler surgery and the possibility to use information about tumor chemosensitivity to plan postoperative chemotherapy and radiotherapy. On this basis we treated Askin tumor with a multimodal approach that included induction chemotherapy. Here we present our favorable results with this schedule of treatments and briefly review salient literature data.

\section{Clinical Summary}

Table 1 summarizes the clinical characteristics and outcomes of 5 patients with Askin tumor treated from 1998 to 2002. Patient 1 had been treated surgically elsewhere for "undifferentiated lung cancer" of the upper left lobe and came to us 3 months later with a supraclavicular recurrence. We gave him a cisplatin-based regimen followed by radiotherapy and obtained a complete response. A year later there was a localized chest wall recurrence, so we completed the left upper lobectomy with chest wall resection. Pathologic examination of the specimen demonstrated Askin tumor, and appropriate adjuvant chemotherapy was also given. A cycle of concomitant radiotherapy and chemotherapy was given a year later to treat a further local recurrence. At present this patient is alive with disease.

\footnotetext{
From the Thoracic Surgery Division, ${ }^{\mathrm{a}}$ Medical Oncology Division, ${ }^{\mathrm{b}}$ and Division of Radiotherapy, ${ }^{\mathrm{c}}$ European Institute of Oncology, Milan, Italy.

Received for publication June 26, 2002; accepted for publication July 15 , 2002.

Address for reprints: Giulia Veronesi, MD, Department of Thoracic Surgery, European Institute of Oncology, Via Ripamonti 435, 20141 Milan, Italy (E-mail: giulia.veronesi@ieo.it).

J Thorac Cardiovasc Surg 2003;125:428-9

Copyright $\odot 2003$ by The American Association for Thoracic Surgery $0022-5223 / 2003 \$ 30.00+0$

doi: $10.1067 / \mathrm{mtc} .2003 .198$
}

Of the other 4 patients, 2 had their diagnoses made at our center after percutaneous biopsy before treatment, and the other 2 had their diagnoses made elsewhere by surgical biopsy. All of them received preoperative and postoperative chemotherapy alternating two drug regimens (ifosfamide, vincristine, and doxorubicin and ifosfamide and etoposide) for four to six cycles, with additional high-dose ifosfamide, carboplatin, and etoposide in 2 cases (1 before and 1 after the operation). Radical and safe surgical excision was achieved in all these cases, with chest wall resection of one to five ribs and en bloc lung resection when infiltration was present ( 2 cases). Postoperative radiotherapy ( $\geq 60 \mathrm{~Gy}$ ) was given in all but 1 case. The type of adjuvant treatment was chosen on the basis of clinical and pathologic responses to chemotherapy. In particular, high-dose treatment was discussed and offered to those patients with worse prognoses, such as presence of a high percentage of live cells at the postinduction pathologic examination. Radiotherapy was avoided in 1 patient with good prognostic factors. No major toxicity related to chemotherapy was observed, neither were any postoperative complications seen.

Figures 1 and 2 provide a vivid example of the advantages of induction chemotherapy. Patient 4 initially had unresectable, bulky disease, but the lesion could be removed completely after induction chemotherapy.

\section{Discussion}

Compared with the postoperative approach, preoperative chemotherapy favors a more conservative surgical approach and thus better postoperative function, reduces the risk of intraoperative tumor rupture and tumor cell dissemination, increases the probability of complete surgical resection, favors the sterilization of any occult distant spread, and allows pathologic and clinical evaluation of the response, favoring the choice of the best postoperative regimen of chemotherapy and radiotherapy.

In 53 patients with nonmetastatic chest wall primary cancers included in the First Intergroup Ewing Sarcoma Study, ${ }^{2}$ the recurrence rate was lower with induction chemotherapy than with chemotherapy given subsequently. In a retrospective study published in 1996, Sawin and associates ${ }^{3}$ found that preoperative chemotherapy prolonged survival relative to later chemotherapy and was associated with a significant reduction in tumor size that facilitated resection. In 2000 Christiansen and colleagues ${ }^{4}$ reported on 8 patients with Askin tumor and concluded that the best treatment should include preoperative and postoperative chemotherapy, radical surgical resection, and irradiation, generally postoperative but preoperative in selected cases. In their series the 4 


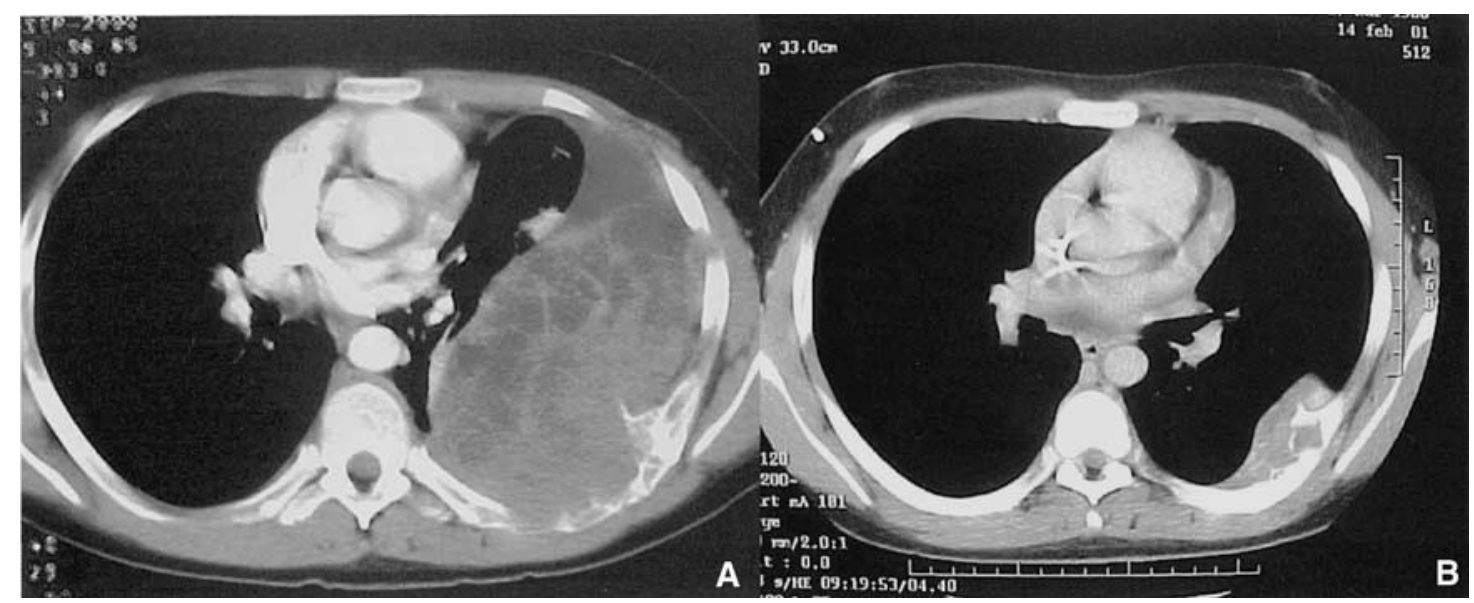

Figure 1. Chest computed tomographic scans of patient 4 before (A) and after (B) chemotherapy, showing impressive response of bulky Askin tumor.

TABLE 1. Clinical characteristics of five patients with Askin tumor

\begin{tabular}{ccccrr}
\hline Patient & $\begin{array}{c}\text { Age (y), } \\
\text { sex }\end{array}$ & Surgery & Therapy & Status & $\begin{array}{c}\text { Survival } \\
\text { (mo) }\end{array}$ \\
\hline 1 & $36, \mathrm{M}$ & LUL + CW (III-V ribs) & S-CT-RT-CT & REC & 3 \\
2 & $22, \mathrm{M}$ & CW (VII rib) & CT-S-HDCT-RT & Died & 13 \\
3 & $14, \mathrm{M}$ & CW (VI-X ribs) & CT-S-CT & NED & 30 \\
4 & $14, \mathrm{M}$ & WR LLL + CW (V-VII ribs) & CT-S-CT-RT & NED & 20 \\
5 & $28, \mathrm{~F}$ & CW (II-IV ribs) & CT-S-RT & NED & 41 \\
\hline
\end{tabular}

$D F I$, Disease-free interval; $M$, male; $F$, female; $S$, surgery; $C T$, chemotherapy; $R T$, radiotherapy; $R E C$, alive with recurrence; $N E D$, no evidence of disease; $W R$ LLL, wedge resection left lower lobe; $L U L$, left upper lobectomy; $C W$, chest wall resection; $H D$, high dose.

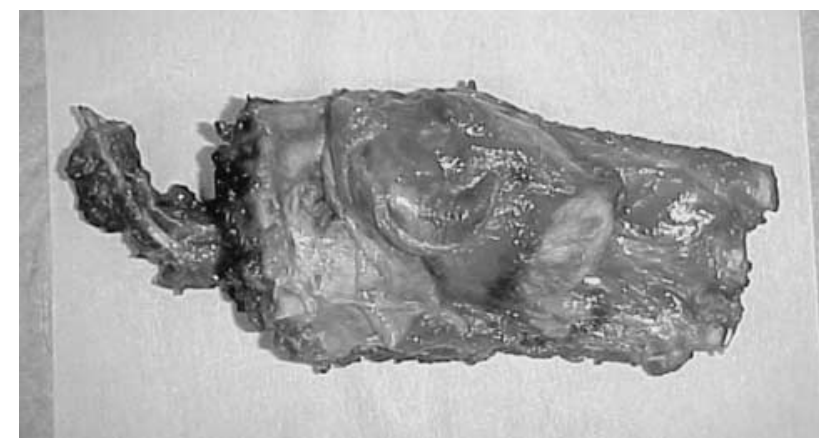

Figure 2. Surgical specimen of Askin tumor from patient 4, including posterolateral sections of three ribs, lesion, and wedge resection of lower lobe.

patients with complete resection were alive at a median follow-up of 30 months, whereas the 4 with extended disease and marginal surgery died, suggesting that complete surgical resection is an important prognostic factor.

Our own experience is fully consonant with these findings. Preoperative chemotherapy was always feasible. In the 4 cases we saw at first diagnosis, it provided high antitumor activity and no major toxicity, allowing complete and safe surgical resection. More appropriate adjuvant treatment was chosen on the basis of pathologic and clinical responses to induction treatment. The example of patient 4 (Figures 1 and 2), who initially had a nonresectable mass but after induction was able to undergo complete surgical resection, is particularly gratifying. We therefore suggest that aggressive treatment with preoperative chemotherapy, radical surgical resection, postoperative chemotherapy, and irradiation is the best approach to Askin tumor.

\section{References}

1. Nesbit ME Jr, Gehan EA, Burgert EO Jr, Vietti TJ, Cangir A, Tefft M, et al. Multimodal therapy for the management of primary, nonmetastatic Ewing's sarcoma of bone: a long-term follow-up of the First Intergroup study. J Clin Oncol. 1990;8:1664-74.

2. Sawin RS, Conrad EU, Park R., Waldhausen JHT. Preresection chemotherapy improves survival for children with Askin tumors. Arch Surg. 1996;131:877-80.

3. Takanami I, Imamura T. The treatment of Askin tumor: results of two cases. J Thorac Cardiovasc Surg. 2002;123:391-2.

4. Christiansen S, Semik M, Dockhorn-Dworniczak B, Rotker J, Thomas M, Schmidt C, et al. Diagnosis, treatment ad outcome of patients with Askin-tumors. Thorac Cardiovasc Surg. 2000;48:311-5. 